\title{
Total $\beta$-Adrenoceptor Deficiency Results in Cardiac Hypotrophy and Negative Inotropy
}

\author{
S. LEE ${ }^{1}$, S. GRAFWEG ${ }^{1}$, T. SCHNEIDER ${ }^{2}$, M. JIMENEZ ${ }^{3}$, J.-P. GIACOBINO ${ }^{3}$, \\ A. GHANEM ${ }^{4}$, K. TIEMANN ${ }^{5}$, W. BLOCH ${ }^{6}$, J. MÜLLER-EHMSEN $^{1}$, \\ R. H. G. SCHWINGER ${ }^{7}$, K. BRIXIUS ${ }^{1,6}$
}

${ }^{1}$ Laboratory of Muscle Research and Molecular Cardiology, Department III of Internal Medicine, University of Cologne, Cologne, Germany, ${ }^{2}$ Institute of Neurophysiology, University of Cologne, Cologne, Germany, ${ }^{3}$ Départment of Medical Biochemistry, Medical Center, University of Geneva, Geneva, Switzerland, ${ }^{4}$ Department of Medicine/Cardiology, University of Bonn, Bonn, Germany, ${ }^{5}$ Clinic C for Internal Medicine, Department of Cardiology and Angiology, University of Münster, Münster, Germany, ${ }^{6}$ Department of Molecular and Cellular Sport Medicine, Institute of Cardiovascular Research and Sport Medicine, German Sport University Cologne, Cologne, Germany, ${ }^{7}$ Medical Clinic II, Weiden, Germany

Received July 13, 2009

Accepted November 25, 2009

On-line April 20, 2010

\section{Summary}

The present study investigated cardiac function in hearts of mice with total deficiency of the $\beta_{1^{-}}, \beta_{2^{-}}$and $\beta_{3^{-}}$-adrenoceptors (TKO) in comparison to wildtype mice (WT). We investigated cardiac morphology and echocardiographic function, measured protein expression of $\mathrm{Ca}^{2+}$-regulatory proteins, SERCA 2a activity, myofibrillar function, and performed running wheel tests. Heart weight and heart-to-body weight ratio were significantly smaller in TKO as compared to WT. This was accompanied by a decrease in the size of the cardiomyocytes in TKO. Heart rate and ejection fraction were significantly diminished in TKO as compared to WT. Protein expressions of SERCA 2a, ryanodine receptor and $\mathrm{Na}^{+} / \mathrm{Ca}^{2+}$-exchanger were similar in TKO and WT mice, but phospholamban protein expression was increased. PKAdependent phosphorylation of phospholamban at serine 16 was absent and CaMKII-dependent phosphorylation at threonine 17 was decreased in TKO. All alterations were paralleled by a decrease in SERCA 2a-activity. A similar maximal calciumdependent tension but an increased myofibrillar calciumsensitivity was measured in TKO as compared to WT. We did not observe relevant functional impairments of TKO in running wheel tests. In the absence of $\beta$-agonistic stimulation, SERCA 2a activity is mainly regulated by alterations of phospholamban expression and phosphorylation. The decreased SERCA 2a activity following $\beta$-adrenoceptor deficiency may be partly compensated by an increased myofibrillar calcium-sensitivity.

\section{Key words}

Beta-1 adrenoceptor • Beta-2 adrenoceptor - Beta-3 adrenoceptor • Knockout • Mice

\section{Corresponding author}

Klara Brixius, Department of Molecular and Cellular Sport Medicine, Institute of Cardiovascular Research, German Sport University Cologne, Carl-Diem-Weg 6, 50933 Cologne, Germany. Fax: +49-221-49828370. E-mail: brixius@dshs-koeln.de

\section{Introduction}

$\beta$-adrenergic stimulation is one of the main neurohumoral mechanisms modulating cardiac function in physiological (e.g. exercise) as well as pathophysiological conditions (e.g. heart failure). Three $\beta$-adrenoceptor ( $\beta$-AR) subtypes have been described with the $\beta_{1^{-}}$and $\beta_{2}$-adrenoceptors mediating positive inotropic reactions mainly by stimulating the $\mathrm{G}_{\mathrm{s}}-$ protein/adenylate cyclase/protein kinase A pathway (for review see Wallukat 2002), whereas $\beta_{3}$-adrenergic 
stimulation is coupled to a cardiac release of nitric oxide via activation of the endothelial NO synthase (Brixius et al. 2004, Gauthier et al. 1998, Gauthier et al. 1996, Moniotte et al. 2001), the functional implication of which has still to be clarified.

Beta-adrenergic positive inotropic effects are paralleled by an increase of intracellular systolic $\mathrm{Ca}^{2+}$ concentrations due to an increase in the $\mathrm{Ca}^{2+}$ influx through the L-type $\mathrm{Ca}^{2+}$ channels (Bers 2002), which is subsequently followed by an increase in the $\mathrm{Ca}^{2+}$ release out of the sarcoplasmic reticulum, as well as a decrease in the myofibrillar $\mathrm{Ca}^{2+}$ sensitivity (Brixius et al. 2002, van der Velden et al. 2003) and an increase in the $\mathrm{Ca}^{2+}$ accumulation by the sarcoplasmic reticulum (Bers 2002). The latter can be attributed to an increase in the activity of the sarcoplasmic reticulum $\mathrm{Ca}^{2+}$-ATPase (SERCA 2a) due to an increased phosphorylation of serine 16 (PLBSer16) and threonine 17 (PLB-Thr17) phospholamban (PLB) (Kranias and Solaro 1982, MacLennan and Kranias 2003).

Only recently, a transgenic mouse model was described with chronic deficiency of all three $\beta$-adrenoceptor subtypes (Bachman et al. 2002, 2004, Jimenez et al. 2002, Lee et al. 2008). The mice are viable and are characterized by cold intolerance due to impaired adaptive responses of the brown adipose tissue to cold exposure. We were interested in the regulation of the intracellular $\mathrm{Ca}^{2+}$-homeostasis and myofibrillar function under conditions of chronic $\beta$-adrenergic deficiency. Therefore, we investigated cardiac morphology and echocardiographic function in total $\beta$-adrenoceptor knockout mice in comparison to their isogenic littermates. In addition, we measured protein expression of $\mathrm{Ca}^{2+}$ regulatory proteins, SERCA $2 \mathrm{a}$ activity, myofibrillar function, and performed running wheel tests.

\section{Materials and Methods}

\section{Transgenic animals}

Studies were performed on 12-week-old female $\beta_{1 / 2 / 3}$ AR-KO mice $\left(\right.$ TKO $=\beta_{1 / 2 / 3}$ KO $=\beta_{1}{ }^{-/-} \beta_{2}{ }^{-/} \beta_{3}{ }^{-/}$) compared to the respective wildtype mice (WT = $\left.\beta_{1}{ }^{+/+} \beta_{2}{ }^{+/+} \beta_{3}{ }^{+/+}\right)$. Creation of the TKO-mice has been described before (Jimenez et al. 2002). Mice were maintained at an artificial light/dark cycle at $20-22{ }^{\circ} \mathrm{C}$ with free access to water and standard laboratory chow diet. Following cervical dislocation the hearts were immediately taken out for further experiments and prepared as described below. The investigation conforms with the Guide for the
Care and Use of Laboratory Animals published by the US National Institutes of Health (NIH Publication No. 85-23, revised 1985). The experiments were approved by the local animal ethics committee.

\section{Morphological analysis}

After being weighed the hearts were fixed with $4 \%$ paraformaldehyde, dehydrated with alcohol, embedded in paraffin, and cut into $7 \mu \mathrm{m}$ slices, which were stained with hematoxylin/eosin. For each group four slices of the left anterior wall were obtained and five photographs were taken at 400 fold magnification (Leica DC500) respectively. Cross-sectional areas of five cardiomyocytes were determined by digitizing the images and computerized pixel counting including only nucleated myocytes for the analysis as described by Engelhardt et al. (1999).

\section{Echocardiography}

Transthoracical echocardiography was performed in 3-month-old mice as previously described (Tiemann et al. 2003). Mice were anesthetized with enflurane $(3 \%$ for induction and $0.8-1 \%$ for echocardiography) in $50 \%$ nitrous oxide and $50 \%$ oxygen by face mask. The degree of anesthesia was adapted to minimize cardiodepressive effects. Thus the heart rate during anesthesia was maintained in the physiological range of conscious mice under resting conditions. The core temperature was maintained at $37^{\circ} \mathrm{C}$ using a feedback-controlled heating pad. Echocardiography was performed using a commercially available ultrasound system equipped with a linear array transducer operating at an emission frequency of $15 \mathrm{MHz}$ (harmonic-mode) with frame rates up to $280 \mathrm{~Hz}$ (HDI5000, Philips Medical Systems, Bothell, WA, USA). Analysis included heart rate, left ventricular end-systolic and end-diastolic volume. For calculation of volumes the area-length method was used (Ghanem et al. 2006, Tiemann et al. 2003).

\section{Tissue preparation}

For the preparation of Western blot samples tissue of each heart was prepared as previously described (Munch et al. 1998). Briefly, 25-35 mg of left ventricular myocardial samples were thawed on ice in threefold volume of chilled preparation buffer (in mmol/l: sucrose 300 , phenyl methyl sulfonyl fluoride 1 , piperazine-N,Nbis(2-ethane sulfonic acid) 20, EDTA 1, $\mathrm{P}_{\mathrm{i}}$ 10, $\mathrm{pH}$ 7.4). Care was taken to dissect myocardial tissue from 
connecting tissue, vessels, and pericardium. Samples were homogenized with a glass-teflon homogenizer (Potter Typ RN 24, 350 upm, IKA Labortechnik Stauffen) under constant $4{ }^{\circ} \mathrm{C}$ temperature. The homogenates were immediately shock-frozen in liquid nitrogen and stored at $-80{ }^{\circ} \mathrm{C}$ in freezing buffer (in mmol/l: sucrose 400, $\mathrm{NaH}_{2} \mathrm{PO}_{4} 50$, EDTA 10, piperazineN,N-bis(2-ethane sulfonic acid) 5, 2-amino-2(hydroxymethyle)-1.3.propandiol 5, pH 7.2). Protein content was measured according to Bradford (1976).

\section{Western blot analysis}

For detection of SERCA 2a, PLB, phosphorylated PLB-Ser16, phosphorylated PLB-Thr17, ryanodine receptor and $\mathrm{Na}^{+} / \mathrm{Ca}^{2+}$ exchanger (NCX) in WT and TKO myocardium, immunoblotting techniques were performed as described previously, with slight modifications (Schwinger et al. 1995). Equal amounts of membrane proteins $(10 \mu \mathrm{g})$ were separated by sodium dodecyl sulphate polyacrylamide gel electrophoresis (SDS-PAGE) with $4 \%$ stacking gel and $12 \%$ acrylamide. The linear range of the antibodies used was determined in previous experiments (Schwinger et al. 1995). To control protein load, we performed Coomassie blue staining of the gel. After blotting, we controlled protein transfer using Ponceau red staining of the membrane. For the immunoreaction, the following commercially available primary antibodies were used: anti-SERCA 2a (mouse) from Affinity BioReagents (Golden, CO, USA); antiryanodine receptor (mouse) from Affinity BioReagents; anti-PLB phosphorylated at Ser16 and Thr17 (rabbit), antibodies against sequence RSAIRRASTIEY (residues 919 of PLB, +Y) in which Ser16 or Thr17 is phosphorylated, from Cyclacel (Dundee, UK); anti-PLB (mouse) from Upstate Biotechnology (Dundee, UK), clone A1, anti- $\mathrm{Na}^{+} / \mathrm{Ca}^{2+}$ exchanger (mouse) from Novus Biologicals (Littleton, CO, USA). For detection, after washing procedures with TBST and TBS, a secondary peroxidase-conjugated mouse or rabbit IgG (Sigma) was used where appropriate. To detect antibody binding, an enhanced chemoluminescence assay (Lumi-Light Western Blotting Substrate, Roche, Grenzach, Germany) was used. After exposure to film (Hyperfilm ECL, Amersham Biosciences, Buckinghamshire, UK) and scanning, the bands were quantified by densitometry.

\section{Preparation of the $S R$}

The SR was prepared according to the methods described earlier (Meissner and Henderson 1987,
Sitsapesan and Williams 1990). Myocardial tissue was ground in liquid nitrogen. The following preparation was made at $4{ }^{\circ} \mathrm{C}$ in the cold room. The tissue was chilled in ice-cold homogenization buffer (in mmol/l: sucrose 300, PMSF 1, PIPES 20, EDTA 10 and $\mathrm{NaH}_{2} \mathrm{PO}_{4}$ 50, pH 7.4), containing $\mathrm{NaH}_{2} \mathrm{PO}_{4}$ to inhibit phosphatases, thereby avoiding in vitro PLB dephosphorylation. PMSF irreversibly inhibits serine proteases by sulfonylation of the serine residue in the active site of the protease and thereby avoids protein decomposition. Connective tissue was carefully trimmed away, and myocardial tissue was homogenized with a motor-driven homogenizer (Braun, Melsungen, Germany). The preparations were stored at $-80{ }^{\circ} \mathrm{C}$ in a buffer containing (in mmol/l) sucrose 400 , HEPES 5, Tris 5, EDTA 10 and $\mathrm{NaH}_{2} \mathrm{PO}_{4}$ 50, pH 7.2.

\section{Measurement of SERCA 2 a activity}

Analysis of SERCA 2a activity was carried out according to the method described by Chu et al. (1988), which is based on coupled enzymatic reactions as follows: i) $\mathrm{ATP} \rightarrow \mathrm{ADP}+\mathrm{P}_{\mathrm{i}}$ (this reaction is catalyzed by SERCA 2a), ii) ADP + phosphoenolpyruvate $\rightarrow$ ATP + pyruvate (catalyzed by pyruvate kinase), and iii) pyruvate $+\mathrm{NADH}$ $\rightarrow$ lactate $+\mathrm{NAD}^{+}$(catalyzed by lactate dehydrogenase). The oxidation of NADH was continuously monitored by the decrease in absorbance at $340 \mathrm{~nm}$ with a spectrophotometer (Beckman DU 640). The reaction was carried out in $1 \mathrm{ml}$ at $37{ }^{\circ} \mathrm{C} .20 \mu \mathrm{l}$ of the SR preparation (final protein concentration, $50 \mu \mathrm{g} / \mathrm{ml}$ ) was suspended in $1000 \mu \mathrm{l}$ of the reaction mixture. The reaction mixture had the following composition (in mmol/l: MOPS 21, $\mathrm{NaN}_{3}$ 4.9, EGTA 0.06, $\mathrm{KCl} 100, \mathrm{MgCl}_{2} 3$, phosphoenolpyruvate 1, NADH 0.2 and pyruvate-lactate dehydrogenase LDH enzyme mixture $(8.4 / 12 \mathrm{U}))$. This led to the following concentrations in the cuvette (in mmol/1): MOPS 21, $\mathrm{NaN}_{3}$ 4.9, EGTA 0.06, $\mathrm{KCl} 100, \mathrm{MgCl}_{2} 3$, phosphoenolpyruvate 1, NADH 0.2, sucrose 7, HEPES 0.05, Tris 0.05, EDTA 0.2, PMSF 0.01, PIPES 0.2 and $\mathrm{NaH}_{2} \mathrm{PO}_{4}$ 1, pH 7.2. $\mathrm{CaCl}_{2}$ was added to the reaction mixture to yield the desired free $\mathrm{Ca}^{2+}$ concentrations, calculated according to the method of Fabiato and Fabiato (1979). Calculations performed by this method are an approximation. We did not measure $\mathrm{Ca}^{2+}$ concentrations directly. The reaction was started with ATP ( $1 \mathrm{mmol} / \mathrm{l})$ and was constant over at least $5 \mathrm{~min}$. The basal activity was measured in the absence of $\mathrm{Ca}^{2+}$ and in the presence of EGTA (4 mmol/l) simultaneously. All experiments were carried out in duplicate. Experiments were performed as described before (Schwinger et al. 1995). 
Table 1. Morphometric analysis and echocardiography.

\begin{tabular}{llll}
\hline Parameter & WT & TKO & p-value \\
\hline Body weight $(g)$ & $30.81 \pm 3.08(\mathrm{n}=5)$ & $31.00 \pm 0.94(\mathrm{n}=5)$ & 0.900 \\
Heart weight $(\mathrm{mg})$ & $121 \pm 3(\mathrm{n}=5)$ & $94 \pm 7(\mathrm{n}=5)$ & $<0.001$ \\
Heart to body weight ratio $(\mathrm{mg} / \mathrm{g})$ & $3.96 \pm 0.49(\mathrm{n}=5)$ & $3.02 \pm 0.18(\mathrm{n}=5)$ & 0.004 \\
Cross-sectional area $(\%$ of WT) & $100 \pm 26.3(\mathrm{n}=4)$ & $67.0 \pm 31.6(\mathrm{n}=5)$ & $<0.001$ \\
Heart rate (beats/min) & $403 \pm 24(\mathrm{n}=4)$ & $267 \pm 69(\mathrm{n}=7)$ & 0.005 \\
Left ventricular end-systolic volume $(\mu \mathrm{ll})$ & $7.4 \pm 4.9(\mathrm{n}=4)$ & $15.1 \pm 5.0(\mathrm{n}=7)$ & 0.036 \\
Left ventricular end-diastolic volume $(\mu \mathrm{l})$ & $37.2 \pm 6.1(\mathrm{n}=4)$ & $39.0 \pm 6.2(\mathrm{n}=7)$ & 0.649 \\
Ejection fraction $(\%)$ & $81 \pm 11(\mathrm{n}=4)$ & $62 \pm 9(\mathrm{n}=7)$ & 0.013 \\
\hline
\end{tabular}

\section{Triton X-skinned fibres measurements}

Left ventricular muscle fibres were prepared as previously described (Brixius and Schwinger 2000). Briefly, the fibre bundles (diameter $<0.2 \mathrm{~mm}$ ) were dissected from the left ventricular papillary muscles and permeabilized at $4{ }^{\circ} \mathrm{C}$ for $20 \mathrm{~h}$ in a solution containing $50 \%$ (v/v) glycerol, $1 \%$ Triton $\mathrm{X}$, and (in $\mathrm{mmol} / \mathrm{l}$ ) $\mathrm{NaN}_{3}$ 10, ATP 5, $\mathrm{MgCl}_{2}$ 5, EGTA 4, 1,4-dithioerythritol (DTE) 2 , and imidazole 20 ( $\mathrm{pH} 7.0$ ). Afterwards, the fibres were stored in a similar solution but without Triton $\mathrm{X}$ at $-20{ }^{\circ} \mathrm{C}$. For the experiments, the Triton X-skinned fibre bundles were prepared under the microscope and then mounted isometrically and connected to a force transducer in a perfusion cuvette (Scientific Instruments, Heidelberg, Germany) in relaxation solution (composition in mmol/l: imidazole 20, $\mathrm{Na}_{2} \mathrm{ATP} 10, \mathrm{NaN}_{3}$ 5, EGTA 5, $\mathrm{MgCl}_{2}$ 12.5, dithiothreitol 1, creatine phosphate 10 , creatine kinase $1 \mathrm{mg} / \mathrm{ml}$, free $\mathrm{Ca}^{2+} 10 \mathrm{nM}$, $\mathrm{pH}$ 7.0). Fibre length was adjusted so that resting tension was just threshold (slack position). The fibres were then incubated in contraction solution (composition as above, but with increasing concentrations of free $\mathrm{Ca}^{2+}$ estimated according to the method of Fabiato and Fabiato (1979)). The experiments were performed at room temperature. To normalize force, the absolute force values obtained were divided by the cross-sectional area of the skinned fibres $\left(\mathrm{CSA}=2 \pi \mathrm{r}^{2}\right)$. Experiments were performed as described previously (Brixius and Schwinger 2000).

\section{Measurement of force development}

Force development was measured as described before (Brixius and Schwinger 2000, Guth and Wojciechowski 1986) (experimental setup, Scientific Instruments, Heidelberg, Germany). The relaxation solution contained (in mmol/l) imidazole $20, \mathrm{Na}_{2} \mathrm{ATP} 10$, $\mathrm{NaN}_{3}$ 5, EGTA 5, $\mathrm{MgCl}_{2}$ 12.5, phospho(enol)-pyruvate 5,
NADH 0.6, $\mathrm{P}_{1}, \mathrm{P}_{5}$-di(adenosine 5') pentaphosphate 0.2 (myokinase inhibitor), and cyclopiazonic acid 25, together with pyruvate kinase $100 \mathrm{U} / \mathrm{ml}$ and lactate dehydrogenase $125 \mathrm{U} / \mathrm{ml}$. The contraction solution contained calcium EGTA $5 \mathrm{mmol} / 1$ instead of EGTA. Both solutions were mixed by a gradient mixer so that $\mathrm{Ca}^{2+}$ was successively increased every $30 \mathrm{~s}$. Free $\mathrm{Ca}^{2+}$ concentration was determined by calculator programs designed for experiments in skinned muscle cells (Fabiato and Fabiato 1979). Measurement of developed tension started $3 \mathrm{~s}$ after the solution was exchanged. Developed tension had reached a stable plateau at that time.

\section{Running wheel tests}

Running wheel tests have been shown to be suitable to assess cardiovascular function of transgene mouse models of human cardiovascular diseases (Bernstein 2003). Mice were held in cages for 4 days in quiet surroundings at room temperature of $20-22{ }^{\circ} \mathrm{C}$ having the possibility to exercise on running wheels with free access to water and standard laboratory chow diet. The results were measured by a tachometer attached to the running wheel.

\section{Materials}

All chemicals were of analytical grade or the best grade commercially available. All compounds were dissolved in twice-distilled water and did not change the $\mathrm{pH}$ of the medium.

\section{Statistical analysis}

Data are presented as mean \pm S.D. Data analysis was performed using Student's t-test for paired and unpaired data, where appropriate. Significance was considered at $\mathrm{p}<0.05$ value. 

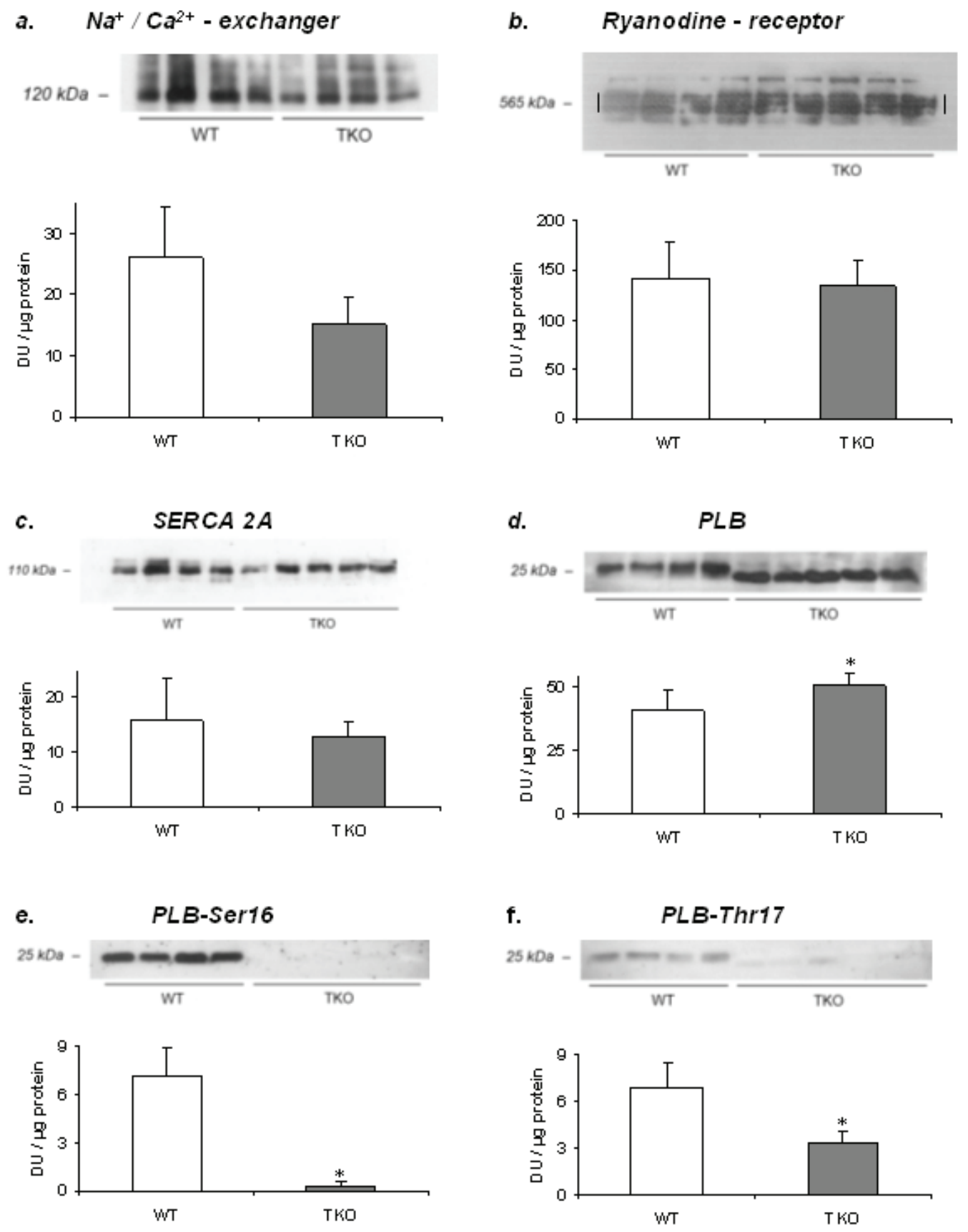

Fig. 1. The protein expression of NCX, ryanodine receptor and SERCA 2a was not significantly changed, whereas PLB $(* p<0.02$ vs. WT) expression was significantly increased and PLB-Ser16 (* $p<0.0001$ vs. WT) and PLB-Ser17 (* $\mathrm{p}<0.005$ vs. WT) expression was decreased in TKO-mice. Data was normalized to calsequestrin expression.

\section{Results}

\section{Morphometric analysis and echocardiography}

Body weight was similar in TKO and WT mice, whereas heart weight and heart-to-body-weight ratio were significantly decreased in TKO mice. In line with these findings, myocyte cross-sectional area was also significantly decreased. Echocardiographic analysis provided evidence that heart rate and ejection fraction were significantly diminished in TKO mice as compared to WT mice. Thus, chronic $\beta$-AR deficiency is accompanied by cardiac hypotrophy as well as negative inotropy and chronotropy (Table 1).

\section{$\mathrm{Ca}^{2+}$ regulatory proteins}

To investigate whether the negative inotropy may be due to alterations of the $\mathrm{Ca}^{2+}$ regulatory proteins, we performed Western blot experiments comparing TKO $(n=5)$ and WT mice $(n=4)$. The expression of the ryanodine receptor, the $\mathrm{Na}^{+} / \mathrm{Ca}^{2+}$ exchanger and of 
a.

Activity

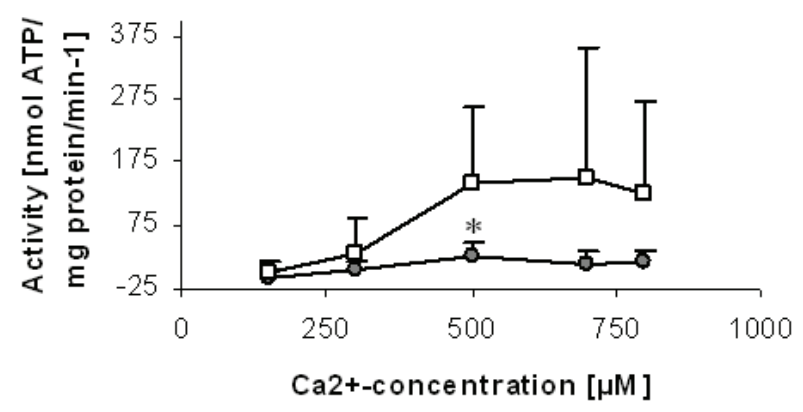

$\rightarrow-T K O-\square-W T$ b.

$V_{\text {max }}$

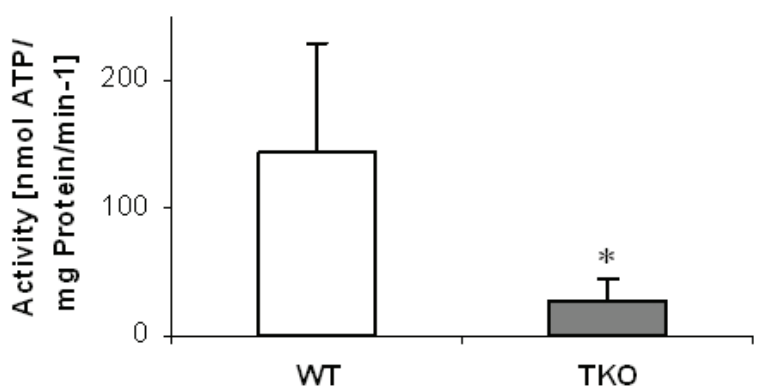

Fig. 2. The maximal activity $\left(V_{\max }\right)$ of SERCA $2 \mathrm{a}$ in TKO mice was $28.1 \pm 16.3 \mathrm{nmol} A T P / \mathrm{mg}$ protein/min ${ }^{-1}(\mathrm{n}=6)$ compared to $144.4 \pm 84.0$ $\mathrm{nmol} \mathrm{ATP} / \mathrm{mg}$ protein $/ \mathrm{min}^{-1}(\mathrm{n}=4)$ in WT mice. The activity of SERCA 2a was significantly decreased in TKO mice $(* \mathrm{p}<0.01 \mathrm{vs}$. WT).

a.

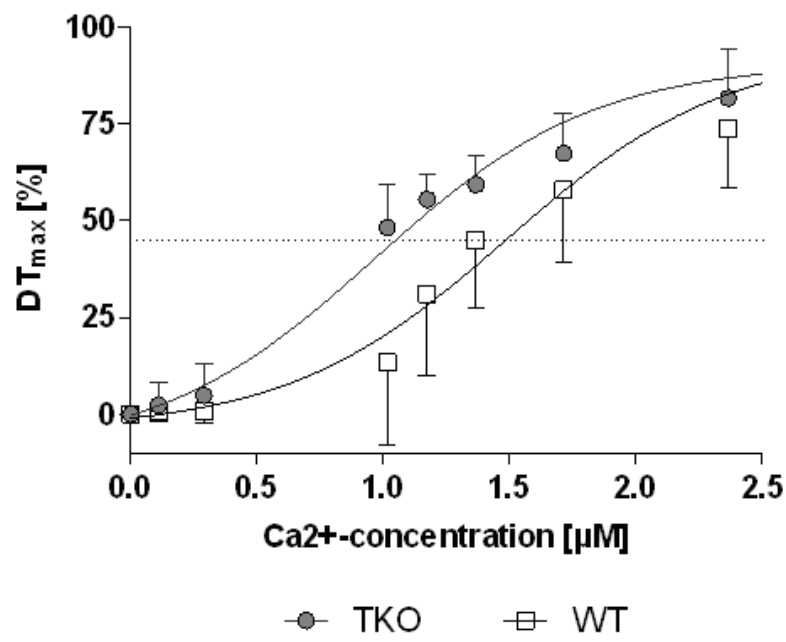

b.

$D T_{\max }$

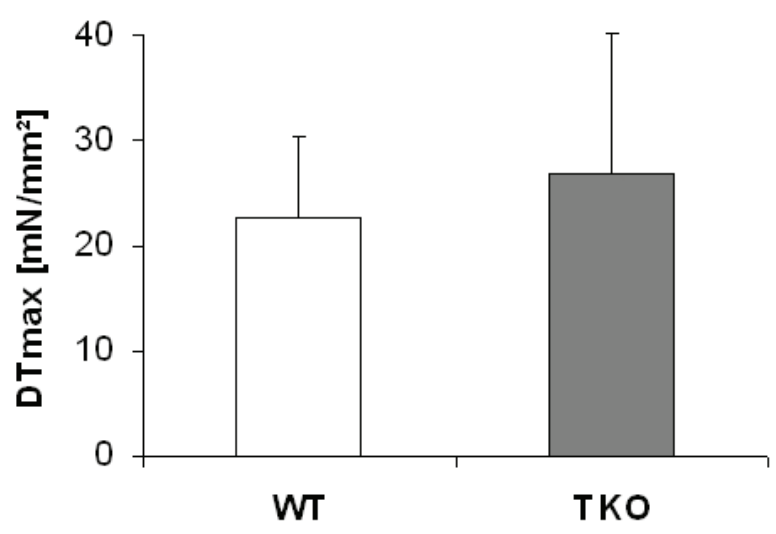

Fig. 3. The maximal force ( $\left.D T_{\max }\right)$ of skinned fibers in TKO mice was similar to WT mice, calcium-sensitivity was significantly increased in TKO mice vs. WT mice.

SERCA 2a were unchanged in the TKO compared to WT mice. The expression of phospholamban was significantly increased, whereas phosphorylation of phospholamban at serine 16 and threonine 17 revealed a marked decrease (Fig. 1). In line with these findings, maximal SERCA 2a activity was significantly decreased in TKO compared to the WT mice (Fig. 2).

\section{Myofibrillar function}

To assess myofibrillar function, we measured $\mathrm{Ca}^{2+}$ sensitivity of skinned fibres in TKO and WT mice by performing measurements of force development of Triton X-skinned fibres within increasing $\mathrm{Ca}^{2+}$ concentrations (Fig. 3). A similar maximal calciumdependent tension (WT 22.6 $27.7 \mathrm{mN} / \mathrm{mm}^{2}, \mathrm{n}=6$; TKO $26.9 \pm 13.4 \mathrm{mN} / \mathrm{mm}^{2}, \mathrm{n}=6$; n.s.), but an increased myofibrillar calcium-sensitivity was found in TKO as compared to WT mice $\left(\mathrm{EC}_{50}\right.$ : WT $1.49,95 \%$ confidence interval 1.36-1.62 $\mu \mathrm{M}, \mathrm{n}=6$; TKO $0.97,95 \%$ confidence interval 0.83-1.11 $\mu \mathrm{M}, \mathrm{n}=6$ ).

Running wheel tests

To investigate the influence of the cardiac alterations observed in TKO mice on the exercise capacity, TKO and WT mice performed a voluntary running wheel experiment. Mean velocity (WT 0.34 
a.

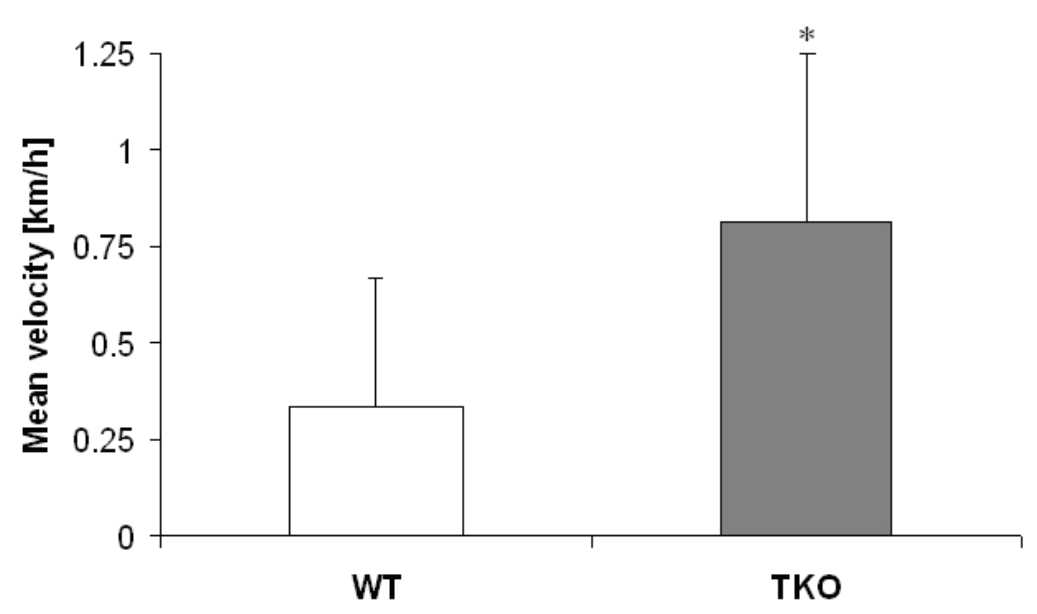

b.

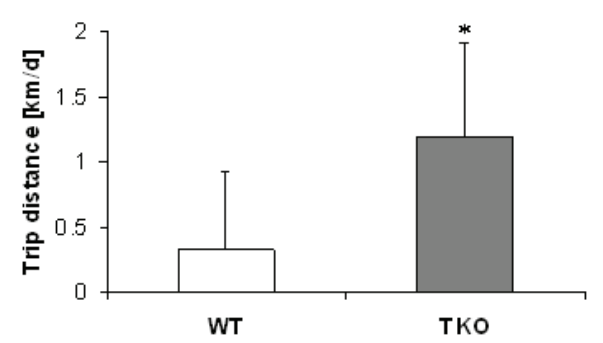

c.

Trip time

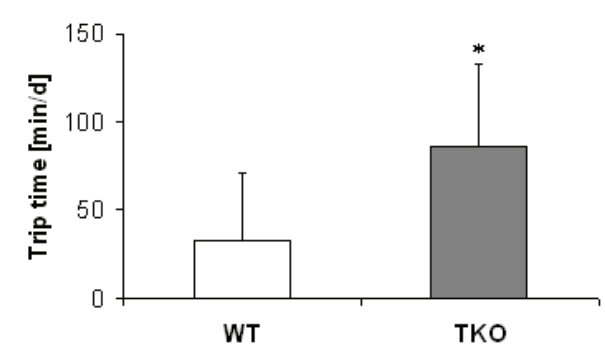

Fig. 4. In running wheel tests there could not be shown any diminished exercise capacity of TKO mice compared to WT mice. An increased willingness to run could be observed in TKO mice which reached statistical significance for mean velocity $(* p<0.04$ vs. WT), trip distance $(* \mathrm{p}<0.03$ vs. WT) and trip time $(* \mathrm{p}<0.04$ vs. WT).

$\pm 0.33 \mathrm{~km} / \mathrm{h}, \mathrm{n}=6$; TKO $0.81 \pm 0.44, \mathrm{n}=6$ ), trip distance (WT $0.33 \pm 0.60 \mathrm{~km} / \mathrm{d}, \mathrm{n}=6$; TKO $1.19 \pm 0.72 \mathrm{~km} / \mathrm{d}, \mathrm{n}=6$ ) and trip time (WT 29.0 $237.7 \mathrm{~min} / \mathrm{d}, \mathrm{n}=6$; TKO 86.6 $\pm 46.5 \mathrm{~min} / \mathrm{d}, \mathrm{n}=6$ ) were significantly increased in TKO as compared to WT mice (Fig. 4).

\section{Discussion}

The present study investigated the influence of $\beta$-adrenoceptor deficiency on cardiac function using a knockout (KO) model. It was shown that the $\beta_{1 / 2 / 3}-\mathrm{KO}$ leads to a significantly decreased heart weight, heart rate and ejection fraction accompanied by altered expression and activity of important $\mathrm{Ca}^{2+}$ regulating proteins. Chronic $\beta_{1 / 2 / 3}$-AR deficiency reduced SERCA 2 a activity by an increase in the expression level of PLB and a diminished PLB-Ser16 and PLB-Thr17 phosphorylation. In spite of these findings, we did not observe relevant functional impairments in running wheel tests but rather an increased willingness to run. The decreased SERCA $2 \mathrm{a}$ activity following $\beta$-adrenoceptor deficiency may be, at least partly, compensated by an increased myofibrillar calcium-sensitivity.

The regulation of cardiomyocyte growth under physiological and pathophysiological conditions is very complex, but one of its controlling signaling pathways is the $\beta$-adrenergic system (MacLellan and Schneider 2000). In $\beta_{1}$-overexpression (OE)-mice, an increased heart-to-body weight ratio was described which led to a substantial hypertrophy of cardiomyocytes and a concomitant fibrosis (Engelhardt et al. 1999). While in early studies $\beta_{2}$-OE-animals did not seem to have any morphological differences compared to their WT, it was shown in later studies that overexpression of the $\beta_{2}$ adrenoceptor was linked with cardiac hypertrophy associated with a cumulative mortality of $81 \%$ within 15 months compared to $4 \%$ in WT-mice (Du et al. 2000). $\beta_{3}$-OE-mice featured a decreased heart-to-body weight ratio compared to their WT (Kohout et al. 2001). Whereas overexpression of the various $\beta$-adrenoceptor subtypes alters cardiac morphology, neither the $\beta_{1}$ - nor the $\beta_{3}$-KO-mice had an altered heart-to-body weight ratio 
(Rohrer et al. 1996, Varghese et al. 2000). Recently it could be shown, however, that a $\beta_{1 / 2}$-knockout leads to a decreased heart-to-body weight ratio (Kiriazis et al. 2008). Since the present study also found a decrease in the heart-to-body weight ratio in TKO mice, whereas the $\beta_{1}$ - and $\beta_{3}$-knockouts did not effect the heart-to-body weight ratio at all, it may be concluded that in maintaining a certain myocyte volume there has to be a functional redundancy among the $\beta$-adrenoceptors, so that only a blockade of at least the $\beta_{1}$ - and the $\beta_{2}$ adrenoceptor entails significant changes in the heart-tobody-weight ratio.

Human heart failure is characterized by profound dysregulation of intracellular $\mathrm{Ca}^{2+}$ homeostasis. Thus, structural and functional alterations in the $\mathrm{Ca}^{2+}$ regulatory proteins present in the sarcoplasmic reticulum (SR) have been shown to be strongly involved in the pathogenesis of heart failure (Yano et al. 2005). Although it is a matter of an ongoing discussion whether SERCA $2 \mathrm{a}$ and PLB expression is altered, it can be stated that SERCA 2 a activity is depressed in the setting of human heart failure due to an attenuated PLB-Ser16- and PLBThr17 phosphorylation (Dash et al. 2001, Schwinger et al. 1995). PLB phosphorylation causes a disinhibition of SERCA $2 \mathrm{a}$ resulting in an enhanced diastolic $\mathrm{Ca}^{2+}$ sequestration into the SR (Frank et al. 2003).

The diminished SERCA 2a activity we found in TKO-mice was due to an increased PLB expression and a decreased PLB-Ser16 and PLB-Thr17 phosphorylation. It should be pointed out that PLB-Thr17 phosphorylation was decreased, but not totally absent in $\beta_{1 / 2 / 3}$-deficient mice. For some time it has been discussed whether $\mathrm{Ca}^{2+} /$ calmodulin-dependent protein kinase II (CaMKII)dependent phosphorylation of PLB-Thr17 is reliant on the presence of $\beta$-adrenergic stimulation or not. Whereas some studies came to the conclusion that phosphorylation of PLB-Ser16 and $\beta$-adrenergic stimulation are prerequisites for PLB-Thr17 phosphorylation, other studies reported PLB-Ser16-independent phosphorylation of PLB-Thr17 (for review see Mattiazzi et al. 2005). Finally, the experiments with a phosphatase inhibitor ('okadaic acid') showed, that PLB-Thr17 can indeed be phosphorylated in the absence of significantly elevated cAMP-levels or concomitant PLB-Ser16 phosphorylation (Mundina-Weilenmann et al. 1996). Regarding the $\beta$-adrenoceptor-independent phosphorylation of phospholamban, the important role of type 1 phosphatase (PP1) has to be mentioned. PP1 represents the main SR phosphatase which among others dephosphorylates
CaMKII. This facilitates CaMKII to perpetuate its activity independently of the intracellular $\mathrm{Ca}^{2+}$ concentration (Bradshaw et al. 2003). Thus this mechanism may be responsible for the slightly sustained PLB-Thr17 phosphorylation in TKO mice. Further studies have to verify this assumption.

It is somewhat surprising that such a complex organism, that a mouse represents, can survive without any $\beta$-adrenoceptors. Obviously the organism has other mechanisms besides the $\beta$-adrenergic system by which cardiovascular function can be sustained. One of these mechanisms might be the increased myofibrillar calciumsensitivity which could be found in TKO-mice. Furthermore, studies with $\beta_{1}$-KO-mice could show, that heart rate in these animals is regulated by the vagal tone, therefore by the parasympathetic nervous system (Rohrer et al. 1998). In addition, it has been shown that TKO mice have a reduced metabolic rate compared to WT mice (Bachman et al. 2002). This can be seen as a contributing factor to the reduced cardiac output found in these animals. So despite of a complete knockout of the $\beta$-adrenoceptors the TKO mice still performed even better in the running wheel tests than their WT littermates. Whereas both $\beta_{1}$ and $\beta_{1 / 2}-\mathrm{KO}$-mice showed no differences in exercise capacity in treadmill experiments (Rohrer et al. 1998, 1999), $\beta_{2}$-KO-mice also has an increased exercise capacity (Chruscinski et al. 1999). In these mice during exercise fat burning was increased which led to a prolonged availability of glycogen reserves in the musculature while the body fat content was significantly lower in $\beta_{2}$-KO-mice compared to WT mice. So it seems that the greater exercise capacity of TKO mice may be, at least partly, attributed to the lack of the $\beta_{2}$-adrenoceptors. A limitation of the present study is that the animals were running voluntarily. Therefore, it is possible that our data do not necessarily represent maximal exercise capacity of these animals.

\section{Conclusions}

Despite $\beta$-adrenoceptor deficiency is going along with cardiac hypotrophy and a decrease in cardiac function, willingness to run is not impaired. These results indicate that compensatory mechanisms may be activated to maintain cardiac function in increased cardiac stress situations. These mechanisms have to be focused in future studies.

\section{Conflict of Interest}

There is no conflict of interest. 


\section{Acknowledgements}

The authors would like to thank Mrs. Katja Rösler, Esra Köroglu and Kerstin Schenk for their excellent technical assistance. This publication contains data of the doctoral thesis of S.L.

\section{References}

BACHMAN ES, DHILLON H, ZHANG CY, CINTI S, BIANCO AC, KOBILKA BK, LOWELL BB: $\beta A R$ signaling required for diet-induced thermogenesis and obesity resistance. Science 297: 843-845, 2002.

BACHMAN ES, HAMPTON TG, DHILLON H, AMENDE I, WANG J, MORGAN JP, HOLLENBERG AN: The metabolic and cardiovascular effects of hyperthyroidism are largely independent of beta-adrenergic stimulation. Endocrinology 145: 2767-2774, 2004.

BERNSTEIN D: Exercise assessment of transgenic models of human cardiovascular disease. Physiol Genomics 13: 217-226, 2003.

BERS DM: Cardiac excitation-contraction coupling. Nature 415: 198-205, 2002.

BRADFORD MM: A rapid and sensitive method for the quantitation of microgram quantities of protein utilizing the principle of protein-dye binding. Anal Biochem 72: 248-254, 1976.

BRADSHAW JM, KUBOTA Y, MEYER T, SCHULMAN H: An ultrasensitive $\mathrm{Ca}^{2+} /$ calmodulin-dependent protein kinase II-protein phosphatase 1 switch facilitates specificity in postsynaptic calcium signaling. Proc Natl Acad Sci U S A 100: 10512-10517, 2003.

BRIXIUS K, BLOCH W, POTT C, NAPP A, KRAHWINKEL A, ZISKOVEN C, KORILLER M, MEHLHORN U, HESCHELER J, FLEISCHMANN B, SCHWINGER RH: Mechanisms of $\beta_{3}$-adrenoceptor-induced eNOS activation in right atrial and left ventricular human myocardium. Br J Pharmacol 143: 1014-1022, 2004.

BRIXIUS K, SAVVIDOU-ZAROTI P, MEHLHORN U, BLOCH W, KRANIAS EG, SCHWINGER RH: Increased $\mathrm{Ca}^{2+}$-sensitivity of myofibrillar tension in heart failure and its functional implication. Basic Res Cardiol $\mathbf{9 7}$ (Suppl 1): I111-I117, 2002.

BRIXIUS K, SCHWINGER RH: Modulation of cross-bridge interaction by 2,3-butanedione monoxime in human ventricular myocardium. Naunyn Schmiedebergs Arch Pharmacol 361: 440-444, 2000.

CHRUSCINSKI AJ, ROHRER DK, SCHAUBLE E, DESAI KH, BERNSTEIN D, KOBILKA BK: Targeted disruption of the $\beta_{2}$ adrenergic receptor gene. J Biol Chem 274: 16694-16700, 1999.

CHU A, DIXON MC, SAITO A, SEILER S, FLEISCHER S: Isolation of sarcoplasmic reticulum fractions referable to longitudinal tubules and junctional terminal cisternae from rabbit skeletal muscle. Methods Enzymol 157: 3646, 1988.

DASH R, FRANK KF, CARR AN, MORAVEC CS, KRANIAS EG: Gender influences on sarcoplasmic reticulum $\mathrm{Ca}^{2+}$-handling in failing human myocardium. J Mol Cell Cardiol 33: 1345-1353, 2001.

DU XJ, GAO XM, WANG B, JENNINGS GL, WOODCOCK EA, DART AM: Age-dependent cardiomyopathy and heart failure phenotype in mice overexpressing $\beta_{2}$-adrenergic receptors in the heart. Cardiovasc Res 48: 448454, 2000.

ENGELHARDT S, HEIN L, WIESMANN F, LOHSE MJ: Progressive hypertrophy and heart failure in beta1adrenergic receptor transgenic mice. Proc Natl Acad Sci U S A 96: 7059-7064, 1999.

FABIATO A, FABIATO F: Calculator programs for computing the composition of the solutions containing multiple metals and ligands used for experiments in skinned muscle cells. J Physiol (Paris) 75: 463-505, 1979.

FRANK KF, BOLCK B, ERDMANN E, SCHWINGER RH: Sarcoplasmic reticulum $\mathrm{Ca}^{2+}$-ATPase modulates cardiac contraction and relaxation. Cardiovasc Res 57: 20-27, 2003.

GAUTHIER C, LEBLAIS V, KOBZIK L, TROCHU JN, KHANDOUDI N, BRIL A, BALLIGAND JL, LE MAREC $\mathrm{H}$ : The negative inotropic effect of $\beta_{3}$-adrenoceptor stimulation is mediated by activation of a nitric oxide synthase pathway in human ventricle. J Clin Invest 102: 1377-1384, 1998.

GAUTHIER C, TAVERNIER G, CHARPENTIER F, LANGIN D, LE MAREC H: Functional $\beta_{3}$-adrenoceptor in the human heart. J Clin Invest 98: 556-562, 1996. 
GHANEM A, ROLL W, HASHEMI T, DEWALD O, DJOUFACK PC, FINK KB, SCHRICKEL J, LEWALTER T, LUDERITZ B, TIEMANN K: Echocardiographic assessment of left ventricular mass in neonatal and adult mice: accuracy of different echocardiographic methods. Echocardiography 23: 900-907, 2006.

GUTH K, WOJCIECHOWSKI R: Perfusion cuvette for the simultaneous measurement of mechanical, optical and energetic parameters of skinned muscle fibres. Pflugers Arch 407: 552-557, 1986.

JIMENEZ M, LEGER B, CANOLA K, LEHR L, ARBOIT P, SEYDOUX J, RUSSELL AP, GIACOBINO JP, MUZZIN P, PREITNER F: $\beta_{1} / \beta_{2} / \beta_{3}$-adrenoceptor knockout mice are obese and cold-sensitive but have normal lipolytic responses to fasting. FEBS Lett 530: 37-40, 2002.

KIRIAZIS H, WANG K, XU Q, GAO XM, MING Z, SU Y, MOORE XL, LAMBERT G, GIBBS ME, DART AM, DU XJ: Knockout of $\beta_{1}$ - and $\beta_{2}$-adrenoceptors attenuates pressure overload-induced cardiac hypertrophy and fibrosis. Br J Pharmacol 153: 684-692, 2008.

KOHOUT TA, TAKAOKA H, MCDONALD PH, PERRY SJ, MAO L, LEFKOWITZ RJ, ROCKMAN HA: Augmentation of cardiac contractility mediated by the human $\beta_{3}$-adrenergic receptor overexpressed in the hearts of transgenic mice. Circulation 104: 2485-2491, 2001.

KRANIAS EG, SOLARO RJ: Phosphorylation of troponin I and phospholamban during catecholamine stimulation of rabbit heart. Nature 298: 182-184, 1982.

LEE S, SCHWINGER RH, BRIXIUS K: Genetically changed mice with chronic deficiency or overexpression of the beta-adrenoceptors - what can we learn for the therapy of heart failure? Pflugers Arch 455: 767-774, 2008.

MACLELLAN WR, SCHNEIDER MD: Genetic dissection of cardiac growth control pathways. Annu Rev Physiol 62: 289-319, 2000.

MACLENNAN DH, KRANIAS EG: Phospholamban: a crucial regulator of cardiac contractility. Nat Rev Mol Cell Biol 4: 566-577, 2003.

MATTIAZZI A, MUNDINA-WEILENMANN C, GUOXIANG C, VITTONE L, KRANIAS E: Role of phospholamban phosphorylation on Thr17 in cardiac physiological and pathological conditions. Cardiovasc Res 68: 366-375, 2005.

MEISSNER G, HENDERSON JS: Rapid calcium release from cardiac sarcoplasmic reticulum vesicles is dependent on $\mathrm{Ca}^{2+}$ and is modulated by $\mathrm{Mg}^{2+}$, adenine nucleotide, and calmodulin. J Biol Chem 262: 3065-3073, 1987.

MONIOTTE S, KOBZIK L, FERON O, TROCHU JN, GAUTHIER C, BALLIGAND JL: Upregulation of $\beta_{3^{-}}$ adrenoceptors and altered contractile response to inotropic amines in human failing myocardium. Circulation 103: 1649-1655, 2001.

MUNCH G, BOLCK B, HOISCHEN S, BRIXIUS K, BLOCH W, REUTER H, SCHWINGER RH: Unchanged protein expression of sarcoplasmic reticulum $\mathrm{Ca}^{2+}$-ATPase, phospholamban, and calsequestrin in terminally failing human myocardium. J Mol Med 76: 434-441, 1998.

MUNDINA-WEILENMANN C, VITTONE L, ORTALE M, DE CINGOLANI GC, MATTIAZZI A: Immunodetection of phosphorylation sites gives new insights into the mechanisms underlying phospholamban phosphorylation in the intact heart. J Biol Chem 271: 33561-33567, 1996.

ROHRER DK, CHRUSCINSKI A, SCHAUBLE EH, BERNSTEIN D, KOBILKA BK: Cardiovascular and metabolic alterations in mice lacking both $\beta_{1}$ - and $\beta_{2}$-adrenergic receptors. J Biol Chem 274: 16701-16708, 1999.

ROHRER DK, DESAI KH, JASPER JR, STEVENS ME, REGULA DP Jr, BARSH GS, BERNSTEIN D, KOBILKA BK: Targeted disruption of the mouse $\beta_{1}$-adrenergic receptor gene: developmental and cardiovascular effects. Proc Natl Acad Sci USA 93: 7375-7380, 1996.

ROHRER DK, SCHAUBLE EH, DESAI KH, KOBILKA BK, BERNSTEIN D: Alterations in dynamic heart rate control in the $\beta_{1}$-adrenergic receptor knockout mouse. Am J Physiol 274: H1184-H1193, 1998.

SCHWINGER RH, BOHM M, SCHMIDT U, KARCZEWSKI P, BAVENDIEK U, FLESCH M, KRAUSE EG, ERDMANN E: Unchanged protein levels of SERCA II and phospholamban but reduced $\mathrm{Ca}^{2+}$ uptake and $\mathrm{Ca}^{2+}$-ATPase activity of cardiac sarcoplasmic reticulum from dilated cardiomyopathy patients compared with patients with nonfailing hearts. Circulation 92: 3220-3228, 1995.

SITSAPESAN R, WILLIAMS AJ: Mechanisms of caffeine activation of single calcium-release channels of sheep cardiac sarcoplasmic reticulum. J Physiol Lond 423: 425-439, 1990. 
TIEMANN K, WEYER D, DJOUFACK PC, GHANEM A, LEWALTER T, DREINER U, MEYER R, GROHE C, FINK KB: Increasing myocardial contraction and blood pressure in C57BL/6 mice during early postnatal development. Am J Physiol 284: H464-H474, 2003.

VAN DER VELDEN J, PAPP Z, ZAREMBA R, BOONTJE NM, DE JONG JW, OWEN VJ, BURTON PB, GOLDMANN P, JAQUET K, STIENEN GJ: Increased $\mathrm{Ca}^{2+}$ sensitivity of the contractile apparatus in endstage human heart failure results from altered phosphorylation of contractile proteins. Cardiovasc Res 57: 3747, 2003.

VARGHESE P, HARRISON RW, LOFTHOUSE RA, GEORGAKOPOULOS D, BERKOWITZ DE, HARE JM: $\beta_{3^{-}}$ adrenoceptor deficiency blocks nitric oxide-dependent inhibition of myocardial contractility. J Clin Invest 106: 697-703, 2000.

WALLUKAT G: The beta-adrenergic receptors. Herz 27: 683-690, 2002.

YANO M, IKEDA Y, MATSUZAKI M: Altered intracellular $\mathrm{Ca}^{2+}$ handling in heart failure. J Clin Invest 115: 556-564, 2005. 